\title{
Genetics and Characteristics of a Pigmentation Defective Laboratory Strain of the Lady Beetle, Coleomegilla maculata
}

\author{
Margaret Louise Allen, Joseph Grey Ballenger \\ US Department of Agriculture, Agricultural Research Service, Biological Control of Pests Research Unit, \\ Stoneville, MS, USA \\ Email: meg.allen@ars.usda.gov
}

Received 16 June 2014; revised 23 July 2014; accepted 4 August 2014

Copyright (C) 2014 by authors and Scientific Research Publishing Inc.

This work is licensed under the Creative Commons Attribution International License (CC BY).

http://creativecommons.org/licenses/by/4.0/

(c) (i) Open Access

\begin{abstract}
Beetles in the family Coccinellidae, commonly known as ladybugs, lady beetles, or ladybirds, are easily identifiable and popular beneficial insects. Current research aims to support conservation efforts of beneficial insects in agroecosystems by exploring genetic processes related to nutrition. As a part of this research, colonies of Coleomegilla maculata have been maintained in culture and inbred over many generations since 2009. One result of this inbreeding has been the discovery of novel morphological phenotypes unique to laboratory strains or present in wild populations at such low levels that they have not yet been described. One such phenotype is described here. The strain described here, ye (yellow elytra and eyes) was characterized with classical Mendelian breeding and digital image analysis. This phenotype differs from wild populations by possessing yellow pigment in the elytra and pale grey to white eyes. In contrast, wild populations of $C$. maculata possess pink or red pigmented elytra with black spots, and black eyes. C. maculata is not known to exhibit polymorphism in the field. Inheritance is autosomal and recessive. This species was not previously known to exhibit the dramatic variation of color described here. The strain is stable in the homozygous recessive form, and retains laboratory rearing characteristics similar to the wild type laboratory strain.
\end{abstract}

\section{Keywords}

Coccinellidae, Yellow, Autosomal, Recessive, Elytra, Eye Color, Inbreeding, Heritable Trait, Pigmentation, Mutant Phenotype, Cuticle

\section{Introduction}

The species complex Coleomegilla maculata DeGeer (Coleoptera: Coccinellidae) is commonly found in North

How to cite this paper: Allen, M.L. and Ballenger, J.G. (2014) Genetics and Characteristics of a Pigmentation Defective Laboratory Strain of the Lady Beetle, Coleomegilla maculata. Advances in Entomology, 2, 161-166.

http://dx.doi.org/10.4236/ae.2014.24024 
American agroecosystems and widespread on the North American continent. It is a highly polyphagous species and is important in regulating pest insect populations by consuming many soft bodied insects including in its diet pollen, mites, aphids and moth eggs [1]. While performing serial isofemale selections with the goal of increasing homozygosity in a laboratory strain of $C$. maculata, a small number of insects that appeared to have yellow coloration rather than the normal pink to red were found.

\section{Materials and Methods}

\subsection{Insect Cultures and Strain Establishment}

The first three mutant beetles were observed among the progeny of the second generation of inbred beetles. Two males and one female were isolated and inbred, but only produced three viable offspring, all yellow males. These males were crossed to wild type virgin females. All surviving offspring $(n=30)$ exhibited the wild-type, pink/red, phenotype. These putative heterozygotes were crossed as a group, and produced yellow $(n=43)$ and pink $(n=125)$ progeny. Yellow insects were used to found a putatively homozygous colony of phenotypically stable yellow beetles. After the fourth generation of consistent phenotypic strain stability colony was judged sufficiently well established to be characterized with classical genetic crosses. The mutant strain was designated ye, for yellow elytra and eyes. Crosses were performed to test the hypothesis that the genetic basis of the phenotype was monofactorial.

\subsection{Digital Images and Analysis}

Images were collected using a Nikon Stereomicroscope SMZ1500 (Nikon Corporation, Tokyo, Japan) with the aperture fully closed for maximum depth of field (WD54 1x objective, C-W10xA/22 oculars, and 0.75 - 2 zoom). A Nikon NI-150 high intensity double gooseneck illuminator set at 75\% intensity illuminated the subjects from opposing sides. A Nikon digital camera, DMX 1200, with factory supplied ACT-1 software was used to collect images (1/25 sec shutter speed). Images used to analyze cuticle color were cropped to include only the pink or yellow sections of the elytra (forewings) and converted to JPG files then analyzed using RGB software [2].

\section{Results}

Results of crosses are shown in Table 1. Phenotypic ratios did not differ from the 3 pink to 1 yellow expected from the crossing of heterozygous individuals with a single locus mutation [3]. No evidence of sex linkage was indicated by any of the crosses; both male and female individuals of each phenotype were produced in all offspring. Thus we conclude that the locus is autosomal. Digital images were collected and analyzed for future reference (Figure 1). At the time of the manuscript preparation, the yellow ye strain was stable and robust. Laboratory rearing characteristics of the strain do not obviously differ from the wild type laboratory strain (empirical observation). Egg hatch and pupation rates (Table 1(c)) are similar to those of the wild type strain, under laboratory conditions. Loss of pigmentation in eyes is visible in the advanced embryo stage an in hatching neonates, as shown in Figure 2.

Four sections of each sampled individual were used for color analysis (see Figure 1(b), Figure 1(c)). Color samples were cropped from colored areas between the melanized spots on the elytra. Averaged trichromatic color percentages are shown in Table 2 as Red (\% R), Green (\% G), or Blue (\% B) as detected by the digital camera. A composite of pixel components are also shown. The mutant strain, while appearing yellow visually, differed from wild-type primarily in the values for green and blue pixels. Mature specimens, with completed pigmentation deposition in the wings had higher green (Student t-test, $\mathrm{p}<0.0001$ ) and blue (Student t-test, $\mathrm{p}<$ 0.0001) pixel values when measured as live whole specimens. Chemical characterization of pigments in mutant and wild-type strains is in progress using chemical and physical extraction and isolation methods.

\section{Discussion}

This trait is of interest to insect dieticians because some Coccinellids possess carotenoid pigments [4] [5]; however no biochemical studies have focused on C. maculata. Light coloration and the ability to produce eggs when reared on an artificial diet without prey supplementation are correlated in some Coccinellids (i.e. Harmonia axiridis and C. maculata, but not Hippodamia or Coccinella sp.) [6] indicating that carotenoids may be essential for 
Table 1. Crossing experiments between two strains of lady beetles, Coleomegilla maculata. (a) Expected results of crosses betweeen wild type pink (+) and variant yellow (ye), based on the null hypothesis that a single autosomal allele is responsible for the phenotype. (b) Results from paired matings. Analyses indicating a "do not reject the null hypotheses" supporting a single autosomal allele controlling the phenotype are shown as ns (not significant). wt = wild type, $\mathrm{f}=$ female, $\mathrm{m}=$ male, $\mathrm{G}=$ generation, $\mathrm{R}=$ reciprocal, $\mathrm{y}=$ yellow, $\mathrm{F}=$ filial, avg = average. (c) Hatch rate and pupation rate of crossing experiments. No significant differences were identified (Student t-test, $\mathrm{p}>0.05$ ) between the homozygous recessive cross nor reciprocal crosses in either hatch or pupation rates as compared with the wild type strain.

(a)

\begin{tabular}{|c|c|c|c|}
\hline \multicolumn{4}{|c|}{ Phenotype $+=$ pink ye $=$ yellow } \\
\hline Male Parent & Female Parent & Offspring Ratio & Phenotype \\
\hline++ & ++ & $++100 \%$ & pink \\
\hline yeye & yeye & уеуе $100 \%$ & yellow \\
\hline$+y e$ & yeye & $1: 1^{*}$ & pink: yellow \\
\hline yeye & $+y e$ & $1: 1^{*}$ & pink: yellow \\
\hline$+y e$ & $+y e$ & $3: 1$ & pink: yellow \\
\hline++ & yeye & +ye $100 \%$ & pink \\
\hline yeye & ++ & + ye $100 \%$ & pink \\
\hline
\end{tabular}

*cross not performed.

(b)

\begin{tabular}{|c|c|c|c|c|c|c|c|c|c|c|c|}
\hline $\begin{array}{l}\text { Cross } \\
\text { number }\end{array}$ & $\begin{array}{l}\text { Female } \\
\text { name }\end{array}$ & Male name & $\begin{array}{l}\text { Assumed } \\
\text { female } \\
\text { genotype }\end{array}$ & $\begin{array}{l}\text { Assumed } \\
\text { male } \\
\text { genotype }\end{array}$ & $\begin{array}{l}\text { Number } \\
\text { of eggs } \\
\text { laid }\end{array}$ & $\begin{array}{l}\text { Number } \\
\text { of eggs } \\
\text { hatched }\end{array}$ & $\begin{array}{l}\text { Number of } \\
\text { adults } \\
\text { reaching } \\
\text { maturity }\end{array}$ & $\begin{array}{l}\text { Expected color } \\
\text { ratio based on } \\
\text { model } \\
\text { (pink:yellow) }\end{array}$ & $\begin{array}{c}\text { Observed } \\
\text { color ratio in } \\
\text { F1 offspring } \\
\text { (pink:yellow) }\end{array}$ & $\begin{array}{l}\text { Uncorrected } \\
\text { chi-square }\end{array}$ & $\begin{array}{l}\text { F1 hybrid } \\
\text { family } \\
\text { chosen for } \\
\text { F2 }\end{array}$ \\
\hline $\begin{array}{l}\text { Parental } \\
\text { Cross } 0\end{array}$ & P0 f1 & $\begin{array}{l}\text { P0 m1, } \\
\text { P0 m2 }\end{array}$ & yeye & yеyе & 20 & 10 & 3 & $0: 1$ & $0: 3$ & ns & $\begin{array}{l}\text { all (all } \\
\text { male) }\end{array}$ \\
\hline \multicolumn{2}{|c|}{ Out Cross 1 wt f1, wt f2 } & $\mathrm{P} 1 \mathrm{~m} 1$ & ++ & yeye & nc & nc & & & & & \\
\hline \multicolumn{2}{|c|}{ Out Cross 1 wt f3, wt f4 } & $\mathrm{P} 1 \mathrm{~m} 2$ & ++ & yeye & nc & nc & 69 & $1: 0$ & 69:0 & ns & $\begin{array}{c}\text { all } \\
\text { (pooled) }\end{array}$ \\
\hline \multicolumn{2}{|c|}{ Out Cross 1 wt f5, wt f6 } & $\mathrm{P} 1 \mathrm{~m} 3$ & ++ & уеуе & nc & nc & & & & & \multirow[b]{2}{*}{$\begin{array}{l}\text { yellow } \\
\text { only }\end{array}$} \\
\hline \multicolumn{3}{|c|}{$\begin{array}{c}\text { Filial Cross } \\
1\end{array}$} & +ye & +ye & nc & nc & 168 & $3: 1$ & $125: 43$ & ns & \\
\hline Cross R1A & wt fA & G5 mA & ++ & yeye & 244 & 157 & 93 & $1: 0$ & 93:0 & ns & \multirow{3}{*}{$\begin{array}{l}\text { F2 pool } \\
\text { ABC }\end{array}$} \\
\hline Cross R1B & wt fB & G5 mB & ++ & yeye & 186 & 162 & 58 & $1: 0$ & $58: 0$ & ns & \\
\hline Cross R1C & wt fC & G5 mC & ++ & yеyе & 284 & 233 & 90 & $1: 0$ & $90: 0$ & ns & \\
\hline Cross R1D & wt fD & G5 mD & ++ & yеyе & 12 & 0 & infertile & & & & \multirow{4}{*}{$\begin{array}{l}\text { F2 pool } \\
\text { EFG }\end{array}$} \\
\hline Cross R1E & G5 fE & wt mE & yeye & ++ & 242 & 160 & 100 & $1: 0$ & 100:0 & ns & \\
\hline Cross R1F & $\mathrm{G} 5 \mathrm{fF}$ & wt $\mathrm{mF}$ & yeye & ++ & 180 & 131 & 81 & 1:0 & $81: 0$ & ns & \\
\hline Cross R1G & G5 fG & wt mG & yeye & ++ & 157 & 106 & 53 & $1: 0$ & $53: 0$ & ns & \\
\hline Cross R1H & G5 fH & wt mH & yeye & ++ & 67 & 55 & nc & & & & \\
\hline \multirow{2}{*}{$\begin{array}{l}\text { Cross Y1 } \\
\text { Cross Y2 }\end{array}$} & G5 f1 & G5 m1 & yеyе & yеyе & 146 & 84 & 46 & $0: 1$ & $0: 46$ & ns & \\
\hline & G5 f2 & G5 m2 & yеyе & yеyе & 118 & 88 & 17 & $0: 1$ & $0: 17$ & ns & \\
\hline Cross Y3 & G5 f3 & G5 m3 & yeye & yеyе & 64 & 30 & 14 & $0: 1$ & $0: 14$ & ns & \\
\hline \multirow{2}{*}{$\begin{array}{l}\text { Cross wt1 } \\
\text { Cross wt2 }\end{array}$} & wt f1 & wt m1 & ++ & ++ & 89 & 60 & 20 & $1: 0$ & $20: 0$ & ns & \\
\hline & wt f2 & wt m2 & ++ & ++ & 119 & 100 & 27 & $1: 0$ & $27: 0$ & ns & \\
\hline \multirow{2}{*}{$\begin{array}{l}\text { Cross wt3 } \\
\text { Cross wt5 }\end{array}$} & wt f3 & wt m3 & ++ & ++ & 139 & 66 & 37 & 1:0 & $37: 0$ & ns & \\
\hline & wt f5 & wt m5 & ++ & ++ & 28 & 17 & nc & & & & \\
\hline \multirow{2}{*}{$\begin{array}{l}\text { Cross wt6 } \\
\text { Cross } \\
\text { F2ABC }\end{array}$} & wt f6 & wt m6 & ++ & ++ & 46 & 40 & nc & & & & \\
\hline & pooled & pooled & +ye & +ye & 181 & 118 & 88 & $3: 1$ & $67: 21$ & ns & \\
\hline $\begin{array}{l}\text { Cross } \\
\text { F2EFG }\end{array}$ & pooled & pooled & +ye & +ye & 195 & 89 & 60 & $3: 1$ & $44: 16$ & ns & \\
\hline
\end{tabular}


(c)

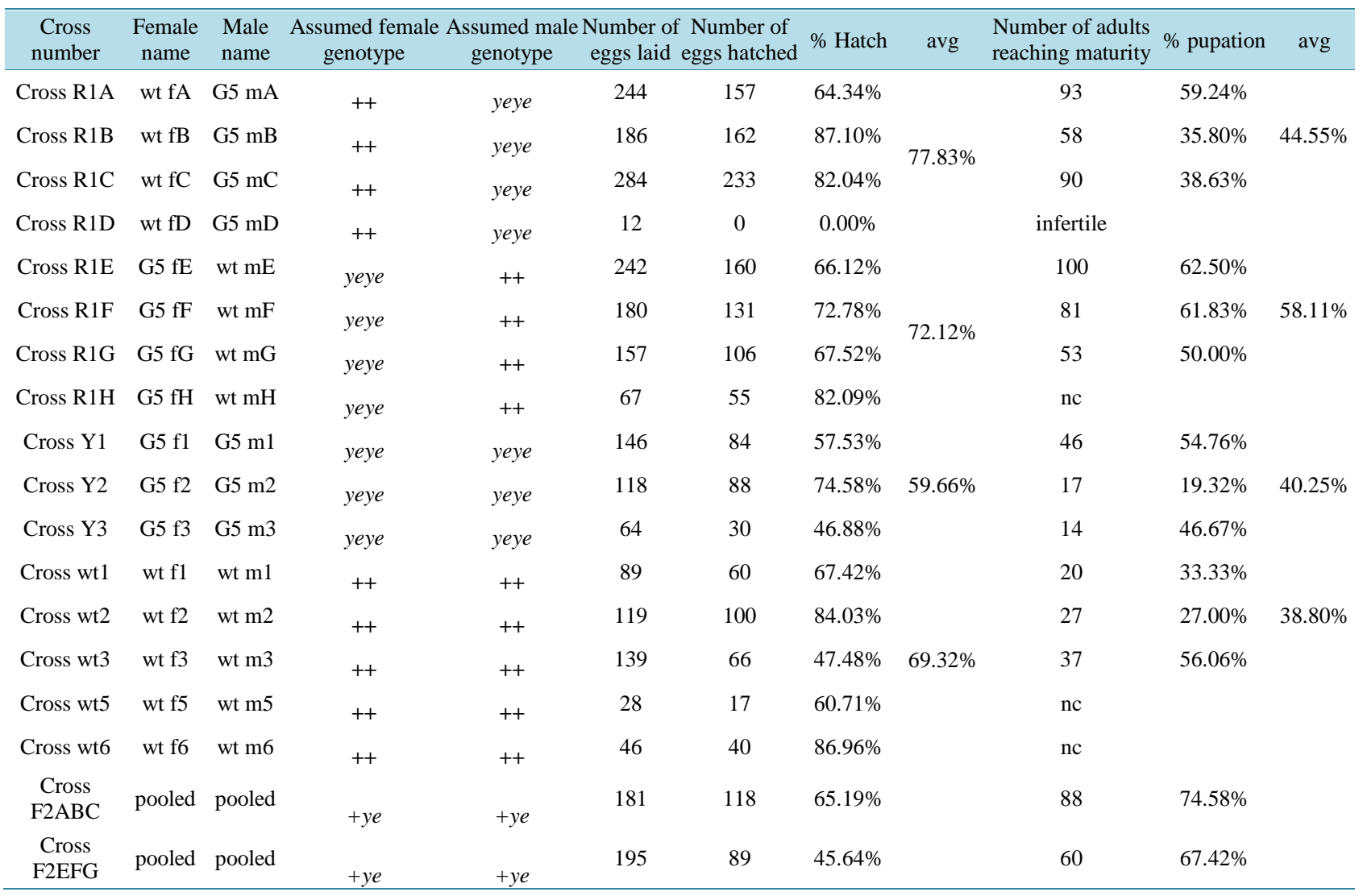

Table 2. Average percentages of RGB values of specimens of yellow or wild type Coleomegilla maculata. Individual specimens are those shown in Figure 1. Specimens 2 and 3 of each strain are newly eclosed adults ( $<24$ hours post adult eclosion), while specimens 4 and 5 are mature adults ( 2 weeks post adult eclosion). Specimen 1 is an "ideal” representative of the phenotype. Computer generated composites are shown.

\begin{tabular}{|c|c|c|c|c|c|}
\hline & sex & $\% \mathrm{R}$ & $\% \mathrm{G}$ & $\%$ B & composite \\
\hline Yellow Specimen 1 & unknown & 41.62 & 34.79 & 23.59 & \\
\hline Yellow Specimen 2 & female & 37.08 & 35.88 & 27.03 & \\
\hline Yellow Specimen 3 & male & 38.05 & 36.08 & 25.85 & \\
\hline Yellow Specimen 4 & female & 40.48 & 35.83 & 23.65 & \\
\hline Yellow Specimen 5 & male & 39.50 & 36.08 & 24.40 & \\
\hline WT Specimen 1 & unknown & 59.11 & 26.28 & 14.62 & \\
\hline WT Specimen 2 & female & 45.68 & 33.88 & 20.48 & \\
\hline WT Specimen 3 & male & 49.00 & 32.25 & 18.80 & \\
\hline WT Specimen 4 & female & 53.65 & 28.90 & 17.45 & \\
\hline WT Specimen 5 & male & 56.85 & 27.78 & 15.40 & \\
\hline
\end{tabular}

egg production. Extensive molecular genetic and biochemical characterization of the yellow family of genes found in the red flour beetle, Tribolium castaneum, identified genes and proteins associated with the elytra, but not with eye color. One phenotype of $T$. castaneum appears visually similar to the mutation described here, glossy, but has not been characterized [7]. Correlation of elytra coloration with levels of toxic defensive compounds has been demonstrated in H. axiridis [8] [9] and Coccinella septempunctata [10]. Defensive chemistry of 

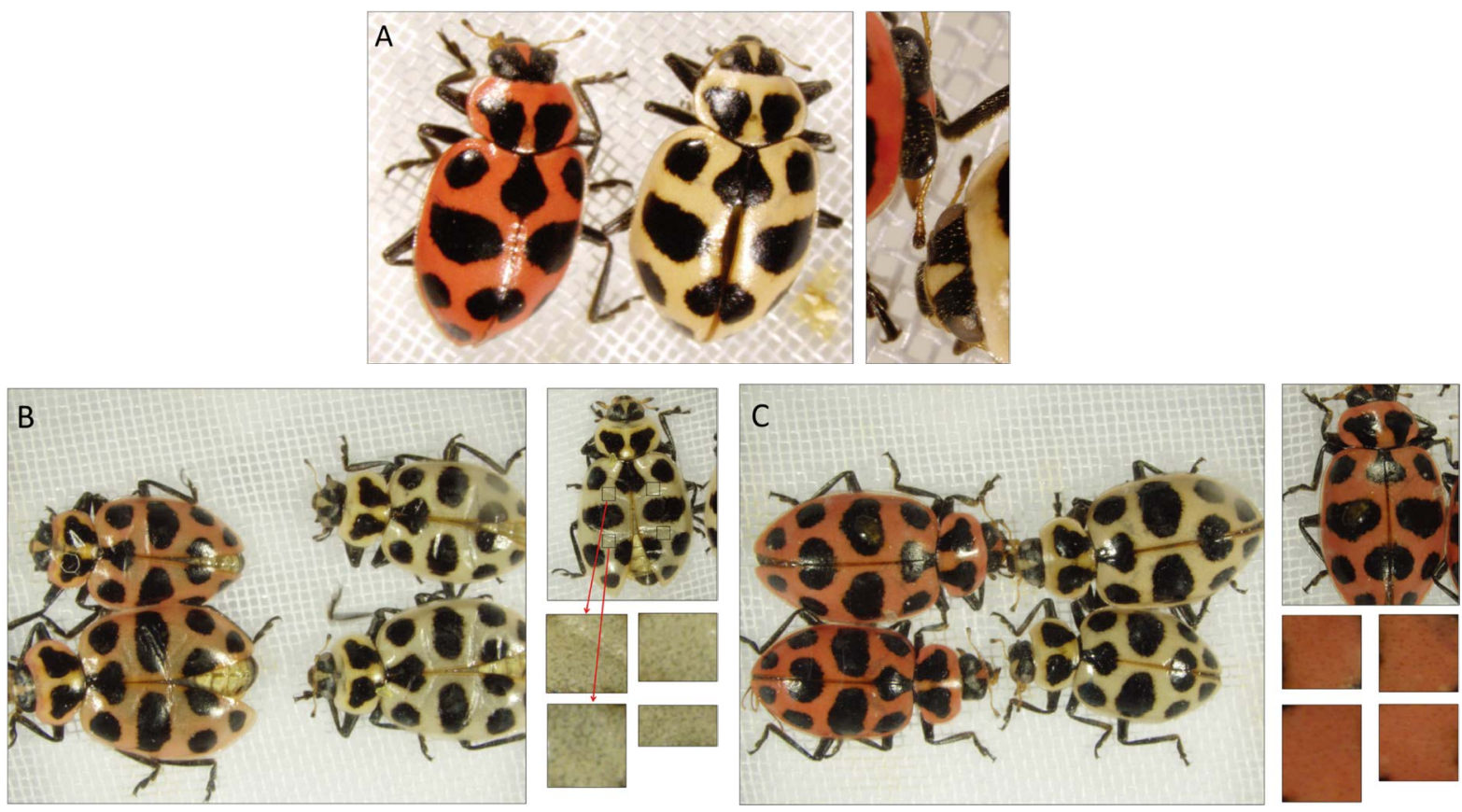

Figure 1. Phenotypes of adult wild type and mutant (ye) specimens of Coleomegilla maculata. (A) Random representative specimens, dorsal view. Left: whole insects; right: close up of heads, showing pale eyes of mutant adult. (B) Newly eclosed (teneral, <24 hours post ecdysis) adults with incomplete pigment deposition and sclerotization (hardening) of elytra. Note bending of soft elytra under the weight of a glass cover slip. (C) Mature adults. (B) and (C) show male (smaller) and female specimens. To the right, subsections of the pigmented elytra sampled for comparative image analysis are shown. Boxes and arrows (B) represent the selections for color samples.
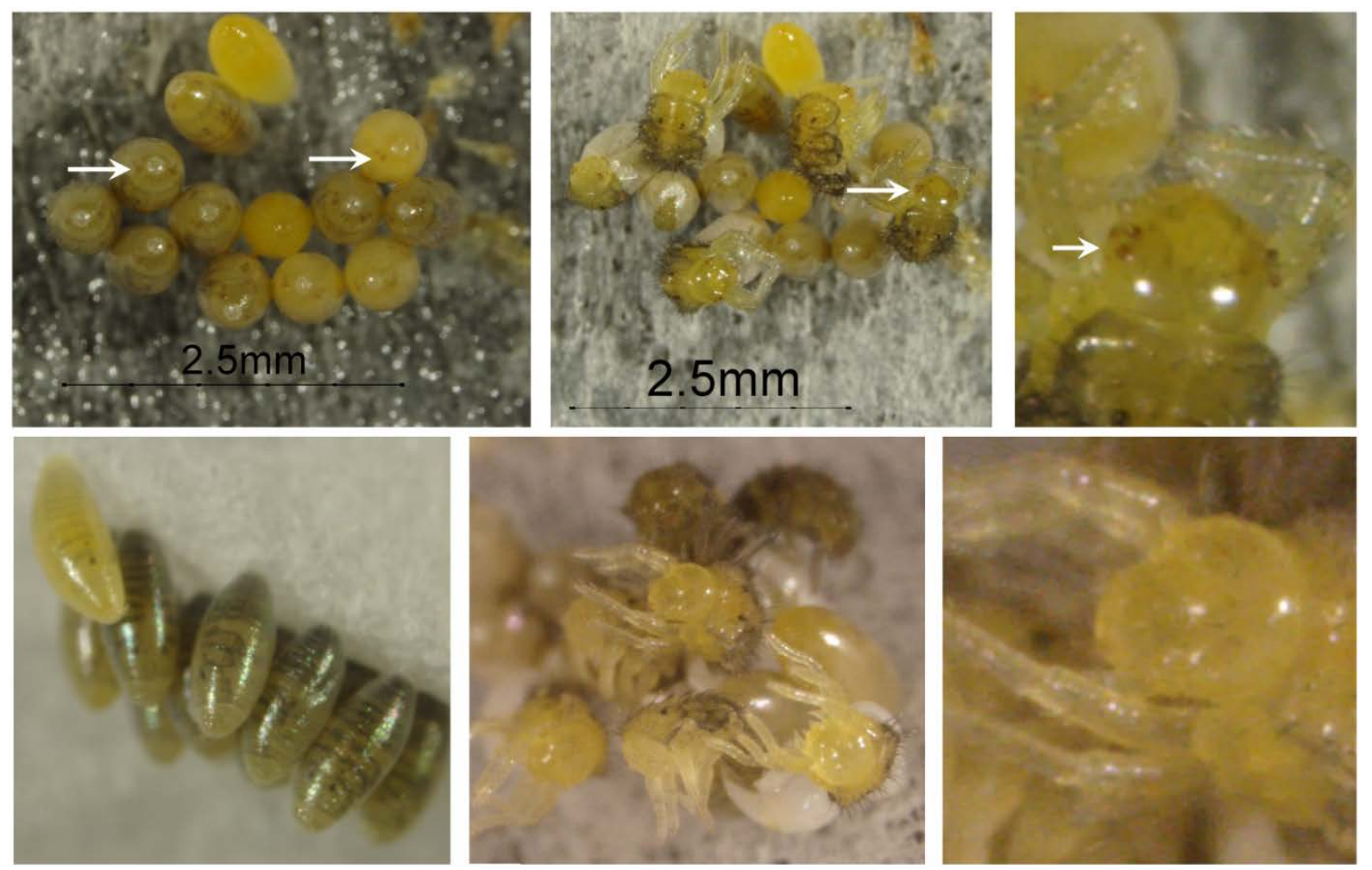

Figure 2. Mature embryos and neonates of wild type and mutant (ye) specimens. Upper images are wild type, lower are mutants. Arrows indicated stemmata, or developing eye-spots. 
coccinellids is of interest to organic chemists and evolutionary biologists.

Elytra color may be involved with the modulation of body temperature. Color forms of Adalia bipunctata with dark elytra are partially responsible for climate tolerance and associated increase in activity influences mate choice in some populations [11]. Color patterns in insect wings are often the product of the co-option of developmental pathways, as exemplified by Heliconius butterflies [12]. Coloration in lady beetles is associated with a range of physiological and ecological traits of interest to biocontrol workers. Transcriptome analyses will shed more light on the relationship between the genetic processes responsible for elytra coloration, and the aforementioned traits in lady beetles. The ye strain will be useful for molecular genetic and biochemical studies of pigments, defensive mechanisms, and evolution of gene regulatory networks. Many studies of $C$. maculata and related Coccinellids will be facilitated by this unique strain of beetles. Better understanding of this important beneficial insect will help farmers and land managers conserve beneficial insects and reduce the need for pesticide applications.

\section{Acknowledgements}

The authors thank Jeff Gore and Brenda Yant for sharing field collected wild insects to found the original $C$. maculata colony from Stoneville, MS. The authors thank the following technical support personnel for assistance with insect maintenance: Fannie Mae Byrd, Catherine Louise Smith, Ebony Williams, and Mary Elizabeth Huddleston. Critical advice concerning lady beetle care was provided by Jonathan Lundgren and Donald Weber. The authors thank Dr. David Taylor of USDA ARS and Dr. Luke Alphey of Oxitec for their helpful suggestions to improve earlier versions of this manuscript. The United States Government has the right to retain a nonexclusive, royalty-free license in and to any copyright of this article. This article reports the results of research only. Mention of a commercial or proprietary product does not constitute an endorsement of the product by the United States Department of Agriculture (USDA). USDA is an equal opportunity provider and employer.

\section{References}

[1] Evans, E.W. (2009) Lady Beetles as Predators of Insects Other than Hemiptera. Biological Control, 51, $255-267$. http://dx.doi.org/10.1016/j.biocontrol.2009.05.011

[2] Byers, J.A. (2006) Analysis of Insect and Plant Colors in Digital Images Using Java Software on the Internet. Annals of the Entomological Society of America, 99, 865-874.

http://dx.doi.org/10.1603/0013-8746(2006)99[865:AOIAPC]2.0.CO;2

[3] Zar, J.H. (1977) Biostatistical Analysis. 3rd Edition, Prentice-Hall, Inc., Upper Saddle River.

[4] Britton, G., Lockley, W.J.S., Harriman, G.A. and Goodwin, T.W. (1977) Pigmentation of the Ladybird Beetle Coccinella septempunctata by Carotenoids Not of Plant Origin. Nature, 266, 49-50. http://dx.doi.org/10.1038/266049a0

[5] Cromartie, R. (1959) Insect Pigments. Annual Review of Entomology, 4, 59-76. http://dx.doi.org/10.1146/annurev.en.04.010159.000423

[6] Obrycki, J.J. and Kring, T.J. (1998) Predaceous Coccinellidae in Biological Control. Annual Reviews of Entomology, 43, 295-321. http://dx.doi.org/10.1146/annurev.ento.43.1.295

[7] Arakane, Y., Dittmer, N.T., Tomoyasu, Y., Kramer, K.J., Muthukrishnan, S., Beeman, R.W. and Kanost, M.R. (2010) Identification, mRNA Expression and Functional Analysis of Several Yellow Family Genes in Tribolium castaneum. Insect Biochemistry and Molecular Biology, 40, 259-266. http://dx.doi.org/10.1016/j.ibmb.2010.01.012

[8] Sloggett, J., Magro, A., Verheggen, F., Hemptinne, J.-L., Hutchison, W. and Riddick, E. (2011) The Chemical Ecology of Harmonia axyridis. BioControl, 56, 643-661. http://dx.doi.org/10.1007/s10526-011-9376-4

[9] Bezzerides, A.L., McGraw, K.J., Parker, R.S. and Husseini, J. (2007) Elytra Color as a Signal of Chemical Defense in the Asian Ladybird Beetle Harmonia axyridis. Behavioral Ecology and Sociobiology, 61, 1401-1408. http://dx.doi.org/10.1007/s00265-007-0371-9

[10] Blount, J.D., Rowland, H.M., Drijfhout, F.P., Endler, J.A., Inger, R., Sloggett, J.J., Hurst, G.D.D., Hodgson, D.J. and Speed, M.P. (2012) How the Ladybird Got Its Spots: Effects of Resource Limitation on the Honesty of Aposematic Signals. Functional Ecology, 26, 334-342. http://dx.doi.org/10.1111/j.1365-2435.2012.01961.x

[11] Hodek, I. and Honek, A. (1996) Ecology of Coccinellidae. Kluwer Academic Publishers, Dordrecht. http://dx.doi.org/10.1007/978-94-017-1349-8

[12] Monteiro, A. (2012) Gene Regulatory Networks Reused to Build Novel Traits: Co-Option of an Eye-Related Gene Regulatory Network in Eye-Like Organs and Red Wing Patches on Insect Wings Is Suggested by Optix Expression. BioEssays, 34, 181-186. http://dx.doi.org/10.1002/bies.201100160 
Scientific Research Publishing (SCIRP) is one of the largest Open Access journal publishers. It is currently publishing more than 200 open access, online, peer-reviewed journals covering a wide range of academic disciplines. SCIRP serves the worldwide academic communities and contributes to the progress and application of science with its publication.

Other selected journals from SCIRP are listed as below. Submit your manuscript to us via either submit@scirp.org or Online Submission Portal.
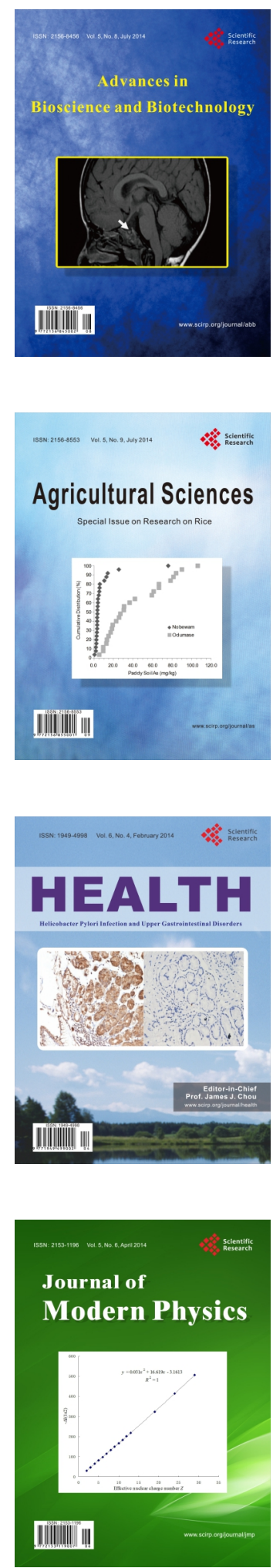
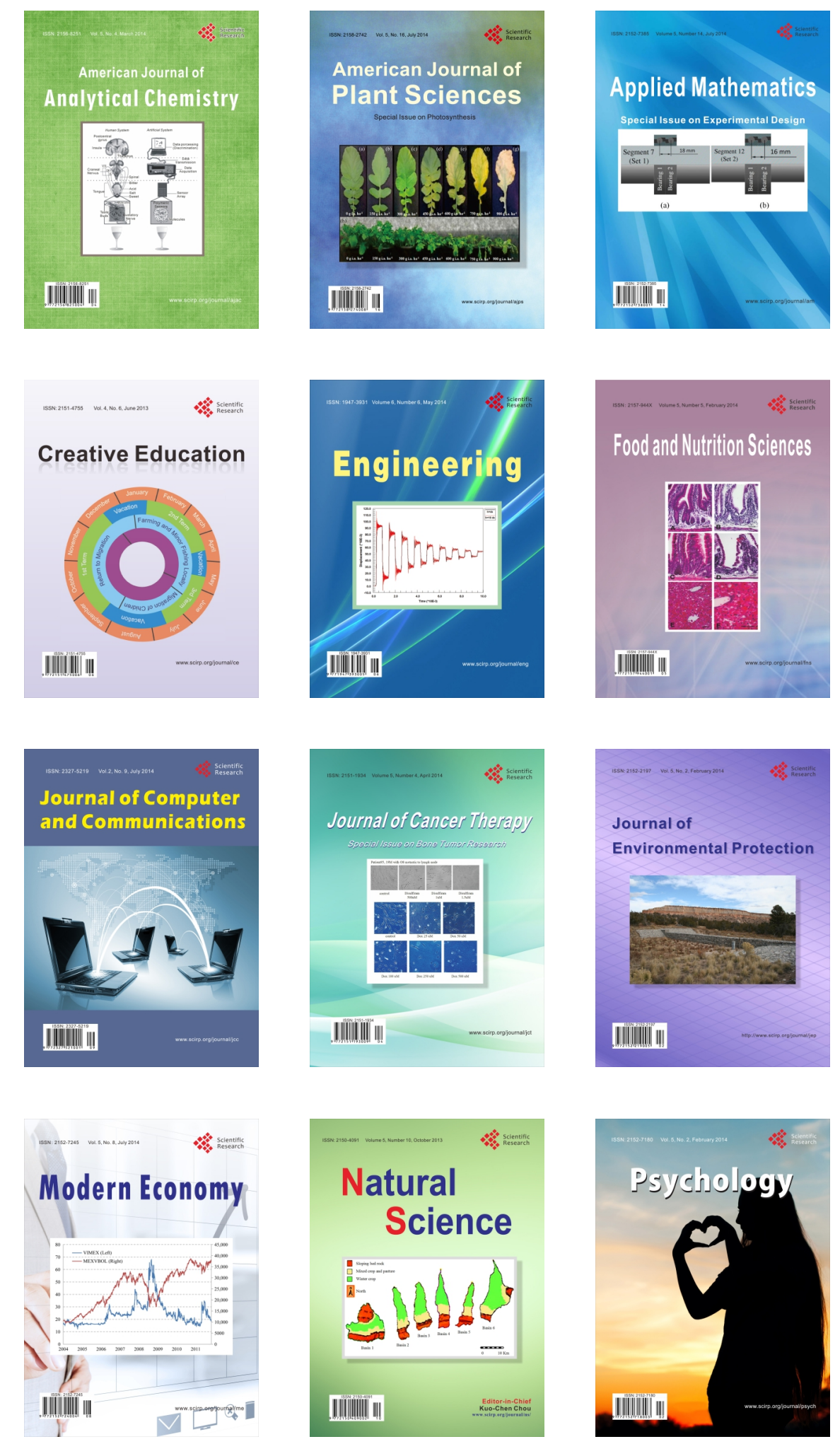